\title{
Determination of tracheal tube insertion depth for dental procedure and oral and maxillofacial surgery
}

\section{Kentaro Ouchi*}

Kyushu University Graduate School, Japan

\section{Introduction}

Incorrect endotracheal placement of the tracheal tube can lead to serious complications, such as laryngeal nerve paralysis and accidental extubation [1]. In oral and maxillofacial surgery and dental procedure, the head of the patient was covered in drape, and an anesthesiologist cannot often see tracheal tube. In addition, surgeon (or dentist) may move the head of the patient. Flexion of the neck results in increase in the insertion depth of tracheal tube [2,3]. Conversely, extension of the neck results in decrease in the insertion depth of tracheal tube [3]. Position of the neck results in the insertion depth of tracheal tube is presented in Figure 1.

Thus, it is necessary to decide exactly a tube position in the oral and maxillofacial surgery and dental procedure. On some tracheal tube, a marker is included on tracheal tubes in the process of manufacture, as an index that the cuff has passed the glottis. The positionof the carina is not taken into consideration when the marker is usedas an index to determineaccuratetubeplacement. On other hand, on some tracheal tube, there is not a marker. Traditionally, to assess the accuracy of tube placement, equality of breath sounds on bilateral chest auscultation has been used for verifying the position of the tube after tracheal intubation in the operating room. The equality of breath sounds on bilateral chest auscultation is a poor diagnostic modality for assessment of endobronchial intubation [4]. And, the distance between the carina and the tube tip cannot be measured. Thus, I recommend continuous breath sound method, this method determine it as reference as the point of changes in breath sounds by continuous chest auscultation.

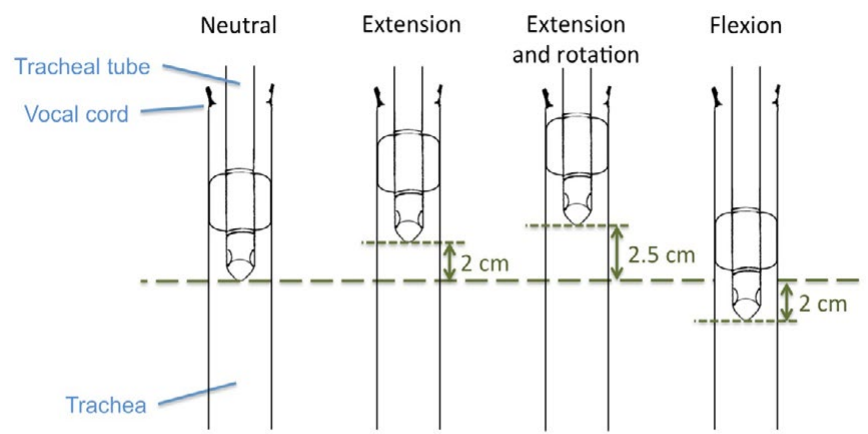

"Flexion of the neck results in increase of $2 \mathrm{~cm}$ in the insertion depth of tracheal tube. Conversely, extension of the neck results in decrease of $2 \mathrm{~cm}$ in the insertion depth of tracheal tube.

"Extension and rotation of the neck results in decrease of $2.5 \mathrm{~cm}$ in the insertion depth of tracheal tube.

Figure 1. Change of head position and displacement of position of the tracheal tube.

\section{Determination of tracheal tube insertion depth with continuous breath sound method}

Anesthesia was induced with sedative anesthetic, analgesic and muscle relaxant. Tracheal Tube was inserted through oral or nasal after lubrication with jelly. Under laryngoscopy, when it was confirmed that the cuff of the tube had passed through the glottis, measurement was made on the tube (Figure 2 (Left)). The measurement of tracheal tube length must assess on the uniformity position, e.g. such as nose or front

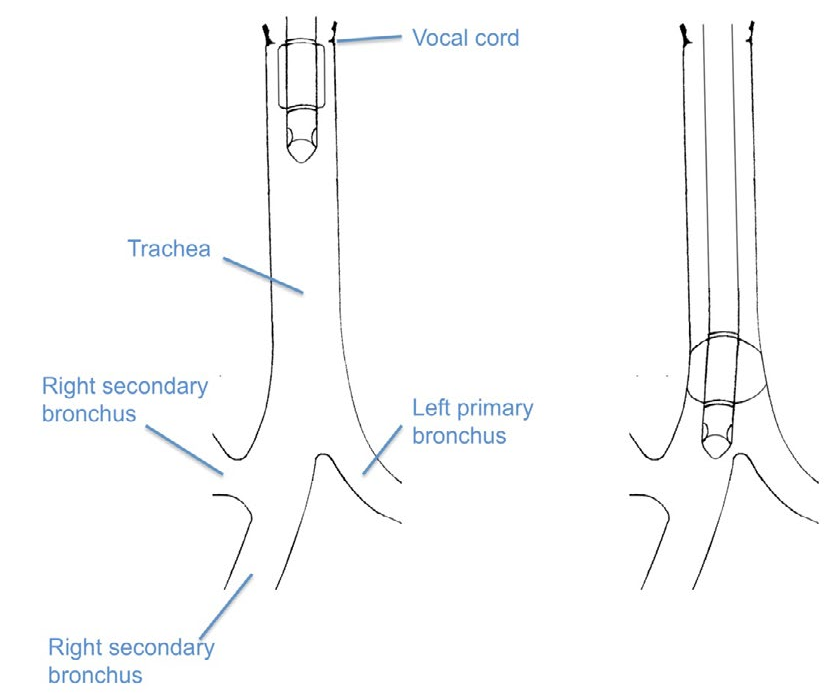

"Under laryngoscopy, it was confirmed that the cuff of the tube had passed through the glottis (left). Breath sounds from the left side of the chest changed in quality (becoming rough, bubbling, wheezing or bronchial) (right).

Figure 2. Process for determination of tracheal tube insertion depth with continuous breath sound method.

Correspondence to: Ouchi K, DDS, PhD, Department of Dental Anesthesiology, Field of Maxillofacial Diagnostic and Surgical Sciences, Faculty of Dental Science, Kyushu University Graduate School, 3-1-1 Maidashi, Higashi-ku, Fukuoka 812-8582, Japan, Tel: +81-92-641-1151, Fax: +81-92-642-6481; E-mail: ken2006anes@yahoo.co.jp

Key words: maxillofacial surgery, dental procedure, tracheal tube

Received: November 12, 2015; Accepted: November 27, 2015; Published: November 30, 2015 
Table 1. Tracheal length $(\mathrm{cm})$ on continuous breath sound method, and on chest radiograph with calculation.

\begin{tabular}{|c|c|c|c|}
\hline ID & On continuous breath sound method & On radiograph & Difference \\
\hline 1 & 13.5 & 13.6 & -0.1 \\
\hline 2 & 13.5 & 12.7 & 0.8 \\
\hline 3 & 14 & 13.7 & 0.3 \\
\hline 4 & 14 & 12 & 2 \\
\hline 5 & 12.5 & 11.7 & 0.8 \\
\hline 6 & 14.5 & 12.1 & 2.4 \\
\hline 7 & 13.5 & 12.7 & 0.8 \\
\hline 8 & 13.5 & 12.6 & 0.9 \\
\hline Mean \pm SD & $13.6 \pm 0.6$ & $12.6 \pm 0.7$ & $1.0 \pm 0.8$ \\
\hline
\end{tabular}

tooth. After the tube was inserted such that about $20 \mathrm{~mm}$ of the tube above the cuff had passed through the glottis, the cuff of the tube was inflated (cuff pressure $20 \mathrm{~cm} \mathrm{H}$ O). The patient's head was placed in the neutral position, following which the tube was further advanced while auscultating bilateral breath sounds with a stethoscope placed on the midaxillary line at the level of the fourth intercostal space, during manual compression of the reservoir bag (airway pressure around $15 \mathrm{~cm}$ $\mathrm{H}_{2} \mathrm{O}$, tidal volume $400-500 \mathrm{~mL}$ ). When breath sounds from the left side of the chest changed in quality (becoming rough, bubbling, wheezing or bronchial), a mark was made on the tube (Figure 2 (Right)). When breath sounds from the left side of the chest disappeared, the tube was withdrawn to the previous position where the change in breath sounds had occurred. At this time, breath sounds from the right side of the chest were examined, and absence of change in the sounds as the tube passed into the left bronchus was confirmed. This made it possible to measure the distance where the cuff passed through the glottis, and the distance at the carina (the point of breath sound change). The distance between tube tip whenfinal decision tracheal tube position and carina desirable more than $2 \mathrm{~cm}$, because flexion of the neck results in increase in the insertion depth of tracheal tube by approximately $2 \mathrm{~cm} \mathrm{[2].} \mathrm{As}$ long as there was a sufficient distance between the glottis and carina (the point of breath sound change), the tube was inserted to a depth of $4 \mathrm{~cm}$ (in the case of an adult) beyond where the cuff passed the glottis. This length was tracheal tube insertion depth using the continuous breath sound method.

\section{Accuracy for continuous breath sound method}

The continuous breath sound method has been used for determining proper tube position after tracheal intubation in the operating room [58]. The continuous breath sound method is applicable to all patients such as adult and pediatric. In particular, it is useful for pediatric patients, because appropriate tube length is different. In the continuous breath sound method, breath sounds changed in the left bronchus as the tube was inserted beyond the carina and entered the right bronchus, because gas flow to the left bronchus through the space between the tube cuff and the right bronchial wall decreased, and breath sounds disappeared because the inflated cuff completely sealed the intubated bronchus, interrupting gas flow to the opposite bronchus [7]. In the continuous breath sound method, when breath sounds disappeared, the tube was withdrawn to its previous position, to the point of change in breath sounds. Therefore, breath sounds changed was indicated the distance to the carina. To indicate position of the carina, it is important that an anesthesiologist to examine by a stethoscope does not miss the chest changed in quality (becoming rough, bubbling, wheezing or bronchial) but not the chest disappeared. Normal breath sounds could be heard from the left side of the chest until the tracheal tube tip was advanced beyond the carina, and inserted into the right bronchus more deeply in the tracheal tube with murphy eye than in the tracheal tube without murphy eye [8]. Tracheal tube with murphy eyemay reduce the reliability of breath sound in detecting.Thus, in the continuous breath sound method, it is necessary to note that, murphy eye produces an error, and not miss the chest changed in quality.

In study of determination of tracheal tube insertion depth with continuous breath sound method, in case of short of the distance from the tube tip to the carina (less than or equal to $2 \mathrm{~cm}$ ), tracheal length was evaluated using a preoperative chest radiograph. The case of short of the distance from the tube tip to the carina was 8 cases, in total 78 cases. Tracheal length on preoperative chest radiographs was calculated using the distance from C6 to the carina and the distance from the glottis to the cricoid cartilage, which is located at C6 $[9,10]$. The mean tracheal length on continuous breath sound method was $13.6 \pm 0.6 \mathrm{~cm}$, the mean tracheal length on chest radiographs with calculation was $12.6 \pm 0.7 \mathrm{~cm}$. Difference between tracheal lengths by two methods was $1.0 \pm 0.8 \mathrm{~cm}$ (minimum 2.4, maximum -0.1) (Table 1). Thus, continuous breath sound method may determine slightly long length than reality. In the breath sounds changed in continuous breath sound method, gas flow to the left bronchus through the space between the tube cuff and the right bronchial wall decreased, and breath sounds disappeared because the inflated cuff completely sealed the intubated bronchus, interrupting gas flow to the opposite bronchus [7]. In other words, absence of a change in breath sounds indicated that ventilation of both lungs was maintained.

\section{References}

1. Fauzdar S, Kraus J, Papageorge M (2011) Vocal cord paralysis following orthognathic surgery intubation. Annals Maxillofacial Surg 1: 166-168. [Crossref]

2. Conrardy PA, Goodman LR, Lainge F, Singer MM (1976) Alteration of endotracheal tube position. Flexion and extension of the neck. Critical Care Medicine 4: 7-12. [Crossref]

3. Sugiyama K, Yokoyama K, Mietani W (1994) Study on displacement of the endotracheal tube and change of head position in general anesthesia. J Japanese Dental Society Anesthesiol 22: 475-490.

4. Brunel W, Coleman DL, Schwartz DE, Peper E, Cohen NH (1989) Assessment of 
routine chest roentgenograms and the physical examination to confirm endotracheal tube position. Chest 6: 1043-1045. [Crossref]

5. Schwartz N (1987) Monitoring bilateral breath sounds. Anesthesiol66:711-712. [Crossref]

6. Sugiyama K, Manabe Y, Kohjitani A (2012) Unrecognized bronchial intubation associated with the uncuffedpediatric tracheal tube with bilateral Murphy eyes. Paediatric Anaesthesia 22: 1191-1196. [Crossref]

7. Sugiyama K, Yokoyama K (1995) Reliability of auscultation of bilateral breath sounds in confirming endotracheal tube position. Anesthesiol 83: 1373. [Crossref]
8. Sugiyama K, Yokoyama K, Satoh K, Nishihara M, Yoshitomi T (1999) Does the Murphy eye reduce the reliability of chest auscultation in detecting endobronchial intubation?. Anesthesia Analgesia 88: 1380-1383. [Crossref]

9. Bennett JD, Guha SC, Sankar AB (1996)Cricothyrotomy: the anatomical basis. J Royal College of Surgeons of Edinburgh 41: 57-60. [Crossref]

10. Mirjalili SA, McFadden SL, Buckenham T, Stringer MD (2012)Vertebral levels of key landmarks in the neck. Clinical Anatomy 25: 851-857. [Crossref]

Copyright: @2015 Ouchi K. This is an open-access article distributed under the terms of the Creative Commons Attribution License, which permits unrestricted use, distribution, and reproduction in any medium, provided the original author and source are credited. 